\section{Bricolagem na criação e trajetória de um circo contemporâneo}

Bricolage in the creation and trajectory of a contemporary circus

Hilka Pelizza Vier Machadoa

a Centro Universitário de Maringá, Maringá, PR, Brasil
Revista Organizações \& Sociedade 2020, 27(93), 314-332

(c) Autor(es) 2020

DOI 10.1590/1984-9270938

ISSN 1984-9230

www.revistaoes.ufba.br

NPGA, Escola de Administração

Universidade Federal da Bahia

Recebido: 20/03/2018

Aprovado: 29/03/2019

\title{
Resumo
}

A bricolagem é uma abordagem que considera que a ação resulta de uma combinação de recursos para novos propósitos, com recursos disponíveis e escassos (Fisher, 2012). O objetivo desta pesquisa foi descrever e analisar o surgimento e a trajetória de um circo contemporâneo como um processo compreendido por meio da abordagem da bricolagem. 0 tipo de pesquisa foi o estudo qualitativo e exploratório, na forma de estudo de caso. Foram utilizadas entrevistas e dados secundários. Os dados foram codificados com auxílio do software $\mathrm{N}$ vivo 9 . A codificação resultou em cinco temáticas: o nascimento do circo - making do; limitações impostas pelo ambiente; a bricolagem network; improvisação e mobilização; e reputação. A principal contribuição teórica foi utilizar a abordagem da bricolagem para explicar o surgimento e a trajetória de um circo contemporâneo, abordando o processo a partir de atores, ações e percepções.

Palavras-chave: Processo; Bricolagem; Circo; Organizações; Emergência de Organizações; Cultura.

\section{Abstract}

Bricolage considers that business creation results from a combination of resources for new purposes from available elements that are scarce (Fisher, 2012). The purpose of this study was to describe and analyze the emergence of a circus by using the bricolage approach to develop explanations in a specific context. The type of research is a qualitative and exploratory study, a case study. Interviews and secondary data were used. Data were analyzed and the coding process was performed using the software Nvivo9 and resulted in five categories: the birth of the circus: making do; limitations imposed by the environment; the network bricolage; improvisation and mobilization; reputation. The main theoretical contribution was to demonstrate how the bricolage approach can be used to explain the emergence of organizations such as the circus, focus on the process, actors, actions and perceptions.

Keywords: Process; Bricolage; Circus; Organizations; Organization Emergence; Culture. 


\section{Introdução}

O circo se apresenta como um campo interessante para estudos organizacionais, por ser uma organização singular e secular difundida pelo mundo, com mais de mil circos (Parker, 2011). Ele se configura como uma forma de organização marcada por continuidade e mudança (Bessone, 2008), o que faz a compreensão desse tipo de organização representar um desafio. Com isso, explicações tradicionais acerca de modos de criação e gestão não produzem avanços na compreensão dessas organizações. A necessidade de deslocar enfoques estáticos em estudos organizacionais e contemplar outras abordagens foi anteriormente apontada por Costa e Saraiva (2012) e Chaerki e Ferreira (2016).

Nesse sentido, a compreensão da ação e do surgimento de organizações como o circo pode ser obtida por meio de estudos de processos (Hjorth, Stradi, Dodd, \& Weik, 2018), os quais levam em consideração atores, suas ações e percepções (Hernes \& Weik, 2007). Nessa vertente aborda-se a bricolagem, que considera a emergência de organizações como resultado da ação de atores que combinam recursos para criar novos propósitos, a partir de elementos disponíveis escassos (Fisher, 2012). Ela representa uma possibilidade para explicar a criação de organizações não sob os preceitos da racionalidade instrumental, voltando-se a explicar como é possível criar algo em uma dinâmica não linear (Garud \& Karnoe, 2003) e com limitação de recursos. 0 termo bricolagem tem sido utilizado por diferentes campos do conhecimento. Por exemplo, no campo da inovação, a bricolagem está associada à criação em contextos de incerteza (Garud \& Karnoe, 2003; Hendry \& Harborne, 2011) e à adaptação (Waal \& Knott, 2013). Ela explica a inovação como resultante de uma postura inovadora gerada a partir da superação de forças que emergem no processo (Senyard, Baker, Steffens, \& Davidsson, 2013).

Por sua vez, o circo é uma organização que utiliza elementos artísticos e criativos para sua criação e sobrevivência. O circo é um lugar de produção de mágicas, marcado por idiossincrasias e representa "certa nostalgia" (Parker, 2011, p. 566). Com estrutura itinerante (Oliveira \& Cavedon, 2013), o circo é uma organização nômade complexa direcionada à produção de emoções (Oliveira \& Cavedon, 2015). Embora móveis, circos não são temporários (Parker, 2011), mas são arranjos organizacionais que buscam sobreviver. Como organizações seculares, eles passaram a ser reconfigurados no século XX, com o surgimento do modelo do circo contemporâneo: "uma combinação de capitalismo empreendedor, marketing de massa, urbanização e transporte de massa" (Parker, 2011, p. 564). O Cirque du Soleil representa uma das principais expressões do circo contemporâneo. Criado em Quebec, transformou-se em uma organização com conselho de administração e planejamento, produção artística global ${ }^{1}$, nos moldes de organizações contemporâneas (Oliveira \& Cavedon, 2017; Sicuro \& Lapierre, 1993). O efeito "soleilzação" do circo (Aguiar \& Carrieri, 2016) demonstra como este, enquanto instituição, tem vivenciado uma transformação identitária.

Algumas transformações ocorreram no circo, mas alguns elementos permanecem e caracterizam a dinâmica desse tipo de organização, como salienta Parker (2011): "mesmo com ar condicionado, venda de ingressos computadorizados e cozinha especializada, o circo apresenta o mesmo tipo de experiência altamente ordenada de desordem" (p. 567). Por essa razão, sua origem e gestão dificilmente poderão ser compreendidas por meio de abordagens gerencialistas. Ademais, como apontam Judice e Furtado (2014), há uma tensão imanente em empreendimentos criativos, entre a produção da arte e o mercado de consumo, sendo que esses empreendimentos se movem sob diferentes racionalidades.

Além disso, em geral, o circo se insere em um ambiente incerto e com recursos limitados, dada a imprevisibilidade da demanda de bens criativos e culturais (Judice \& Furtado, 2014). Entende-se, assim, que é possível um alinhamento aos princípios da bricolagem, que explica como indivíduos agem e lidam com a

1. O Cirque du Soleil se tornou uma multinacional e atua com a industrialização do espetáculo, realizando pesquisas de mercado e buscando os melhores atletas internacionais e sua maximização estética e econômica. Diversificou atividades com a comercialização de DVDs e filmes, espetáculos em navios de cruzeiro. Conta com escritórios em Amsterdam, Singapura e Tóquio (Cordier, 2007; Leslie \& Rantisi, 2011). 
limitação de recursos, com a organização do trabalho e as estruturas de poder e redes, como eles criam valor e dão sentido a suas práticas (Carrieri, 2014; Klerk, 2015). Nesse contexto, enquanto organização, o circo não é impulsionado pela lógica gerencialista da busca pelo crescimento (Seifert \& Vizeu, 2015), então como é possível explicar como circos surgem e se desenvolvem enquanto organizações? Há o pressuposto de que a bricolagem represente uma possibilidade para explicar como se dá o nascimento e a trajetória de organizações como o circo. O objetivo desta pesquisa foi descrever e analisar o surgimento e a trajetória de um circo contemporâneo, como um processo compreendido por meio da abordagem da bricolagem.

Este artigo apresenta os resultados de um estudo qualitativo realizado em um circo contemporâneo que sobrevive há trinta anos. Inicialmente, apresenta-se uma abordagem sobre o circo e seu processo, seguido da descrição de aspectos teóricos que representam os principais fundamentos da bricolagem. Em seguida, após explicação do método, mostraram-se os resultados do caso, que na sequência foi analisado e comentado.

\section{0 circo, organização e processo}

Os primeiros relatos sobre a origem do circo estão associados a desfiles realizados no Egito com animais que vinham da África. Os primeiros teatros a céu aberto tiveram origem na Grécia, e os romanos criaram a nomenclatura "circo", no bojo do sentido da expressão "pão e circo" para o povo. Espetáculos eram assistidos por públicos que compreendiam até 300 mil pessoas. Na idade Média e na Renascença surgiram as figuras dos saltimbancos ${ }^{2}$, grupos de pessoas que viviam de maneira nômade e que iam de cidade em cidade, em feiras e mercados, apresentando espetáculos de acrobacias, malabarismos e domesticação de animais. Esses espetáculos eram também oferecidos para reis da França e de outras nações europeias (Draguignan, 2018). O circo, então, tornou-se o resultado da conjunção da arte equestre inglesa, que era desenvolvida nos quartéis, e de proezas dos saltimbancos (Bolognesi, 2002).

O circo tradicional tem sua formação atribuída a Philip Astley, um oficial da cavalaria inglesa que, em 1768, organizou um espetáculo nas proximidades de Londres, com figurinos elaborados e carrosséis (Bolognesi, 2009b). Anos mais tarde, em 1783, ele abriu, em Paris, o primeiro circo. Depois disso retornou à Inglaterra e a estrutura do circo foi retomada por um italiano. A Astley atribui-se a ação de unir em um picadeiro redondo as exibições equestres às acrobacias e equilíbrios de artistas de rua (Costa, 1999).

Na França, após 1789, a classe burguesa aderiu prontamente ao circo (Bolognesi, 2009b) e, em 1852, foi inaugurado, por Napoleão, o circo Napoleón, que é atualmente o circo mais antigo do mundo, conhecido como Circo de Inverno (Draguignan, 2018). Nesse período, o circo francês teve seus anos dourados. Da França, o circo expandiu para outras capitais europeias, sendo que, em Amsterdam, durante a segunda metade do século XVII, Jacob Bates procurou romper com o modelo de circo popular e criou um espetáculo para atrair autoridades. Com isso, criaram-se as salas de circos fixas (Draguignan, 2018), predominando a circularidade do picadeiro (Bolognesi, 2002).

A partir da segunda metade do século XIX, o papel dos cavalos nos espetáculos deixa de ser central e a acrobacia ocupa maior espaço, dando novo sentido aos espetáculos baseados na ação corporal. Foi também no século XIX que o palhaço foi incorporado ao picadeiro (Bolognesi, 2002), como figura "disforme, que buscava ênfase no ridículo"(p. 8).

Entre a diversidade de modelos de circos encontravam-se também os ambulantes, cuja arte circense era desempenhada por membros de uma mesma família que atuava de modo itinerante, deslocando-se de cidade em cidade - os chamados circos tradicionais, os quais, ao chegarem nas cidades, organizavam os espetáculos dividindo as tarefas entre o grupo. Uma parte do grupo se ocupava do arranjo do acampamento, a outra, da armação da tenda e do palco e, por fim, a terceira preparava um desfile na cidade para anunciar

2. A origem do termo "saltimbancos" provém de "artes do equilíbrio, dos saltos livres ou em bancos" (Costa, 1999, p. 45). 
o espetáculo (Draguignan, 2018). Para Costa (1999), esse caráter itinerante é associado ao circo americano. Salienta o autor que, por volta de 1800, os artistas chegavam aos Estados Unidos e passavam a encenar sob uma lona apoiada sobre uma estrutura móvel, baseada na arquitetura naval, atuando de modo itinerante.

Os espetáculos, no modelo do circo tradicional, não seguiam uma ordem narrativa, mas uma colagem, uma seleção de diferentes técnicas de arte. Cada espetáculo precisava conter uma diversidade de apresentações com palhaços, cavalos, felinos, elefantes, trapezistas e acrobatas. 0 encerramento dos espetáculos ocorria com um número desempenhado em conjunto, por palhaços e acrobatas. A dramatização era assegurada pela música, por objetos redondos ou cômicos e por tambores (Draguignan, 2018), em espetáculos constituídos por sequências de números de atrações (Bolognesi, 2002).

Com a chegada do rádio e da televisão, após a Segunda Guerra Mundial, durante os anos 1950, o circo tradicional começa a enfrentar uma crise de público. Com isso, os artistas oferecem as artes do circo na rua ou em salas de teatro. A pista não é mais circular, como era no modelo tradicional, e o espetáculo se desenrola na forma de um enredo, e não como uma sucessão de números desconectados. Esse momento marca o aparecimento do circo novo e integra outras disciplinas como teatro, dança, artes de rua e marionetes (Cordier, 2007).

No Brasil, as primeiras companhias circenses chegaram no século XIX - acrobatas, saltimbancos e músicos - e se espalharam pelo território (Costa, 1999). Bolognesi (2010) ressalta que o circo teve papel de destaque na consolidação da música popular brasileira. Outro destaque foi a criação, em 1982 no Rio de Janeiro, da Escola Nacional do Circo (Ramos, 2016). No final dos anos 1990 atuavam no país aproximadamente quarenta circos (Bolognesi, 2009a).

Diversas transformações são observadas no circo nesse período. Uma delas é o desaparecimento de animais selvagens nos números exibidos, a outra foi a introdução de uma lógica de continuidade, com a invenção de personagens. Outro traço em relação ao modelo tradicional é a diferença estética, que não é mais voltada apenas ao encanto, mas também à contestação social e à provocação da moral. A identificação do circo no século XX se desenrola sob a violência, a surpresa, o exotismo e as cores. 0 circo contemporâneo pode também representar uma potencial força política (Lavers \& Burtt, 2017).

Cordier (2007) faz referência ao circo contemporâneo como um novo circo, cujo fundamento é o de racionalizar a atividade e propiciar uma inovação estética que, por sua vez, propicia espetáculos cada vez mais sofisticados, que podem ser apresentados em TVs, shows e eventos. Ele estabelece relação com sistemas educacionais credenciados, valoriza treinamentos e estruturas organizacionais. O circo contemporâneo emerge na "ideologia da criatividade e estabelece uma nova forma de humor, transmitida por meio da ideia de desempenho e apresentação de habilidades" (Bessone, 2008, p. 40) com emoções sutis. Enquanto o circo tradicional volta-se para maior autenticidade, o contemporâneo apresenta "complexidade emocional" (Bessone, 2008, p. 38). Mesmo assim, o circo ainda preserva, em suas técnicas, a lógica transcendente do espetacular a fim de impressionar seu público (Kann, 2016).

Apesar das transformações, a arte circense não abandona a utilização do corpo como linguagem e se pauta na perfeição dos movimentos (Ramos, 2016). Para Parker (2011) os circos contemporâneos são "Iugares onde os corpos fazem extraordinárias coisas e coisas extraordinárias são feitas com os corpos, . . . sujeitos a "tratamentos desumanos"' (p. 2). Por meio do treino e da perseverança, "o impossível torna-se possível" e algo pode ser aprendido e conquistado, mesmo que "subvertidos os limites desumanos e forças físicas" (Bessone, 2008, p. 157).

A remodelação do circo não resultou em um único modelo organizacional, sendo que uma pluralidade de formas pode ser observada. Alguns circos, por exemplo, voltam-se para a acrobacia, como o chinês; outros ofertam espetáculos ao ar livre, como os africanos; e outros, ainda, utilizam a cavalaria, como o circo russo. Há circos grandes e pequenos. Os maiores circos do mundo estão nos Estados Unidos e, entre eles, há um que foi criado há 130 anos, exibindo números de cowboys (Draguignan, 2018). Os circos se transformaram, alguns para não desaparecerem e outros passaram à institucionalização (Vermon, 2018). 
Considerando a trajetória milenar e as diferentes configurações que o circo apresenta, estudá-lo enquanto organização a partir de racionalidades instrumentais implicaria em apagar a história de uma instituição cujo saber fazer está contido nas artes e formas de circos atuais, como também em negligenciar a importância da ação tradicional, o que, por sua vez, comprometeria a autonomia do circo enquanto instituição cultural (Magalhães \& Saraiva, 2017). Costa, Barros e Saraiva (2014) ponderam sobre os perigos de aplicação da instrumentalidade no campo da cultura, na medida em que ela representa um recurso de poder. Isso porque a razão instrumental se direciona à busca infindável da produtividade e reforça uma temporalidade "que leva a um sentimento de que tudo se torna transitório, quando na realidade podem existir outras temporalidades, outros saberes, outras formas intersubjetivas não tão deslocadas das relações histórico-sociais" (Carrieri, 2014, p. 41). Isso é importante para o circo, uma organização com longa história e percursos.

Para estudar o circo, princípios do gerencialismo não se adequam (Carrieri, Perdigão, \& Aguiar, 2014). É importante compreendê-lo a partir de uma gestão ordinária e política, capaz de expandir possibilidades do que "significa gerir, gestão" (Carrieri, 2014, p. 52). Para Carrieri, Perdigão e Aguiar (2014), a gestão ordinária pode ser estudada por meio das práticas, que são "significadas no contexto da ação, são historicamente situadas e socialmente reconhecidas, sendo orientadas por normas institucionais e sociais que também as constituem" (p. 707). A abordagem das práticas se fundamenta na visão do processo (Carrieri et al., 2014).

A visão de processo implica em dinamicidade, na medida em que a ontologia do processo se baseia no pressuposto de que o mundo esteja em constante estado de processo (Hernes \& Weik, 2007), envolvendo atores, suas ações e percepções. Atores e organizações não são empiricamente separados, o foco está em compreender como eles se produzem, cada um e em conjunto no âmbito das interações (Helin, Hernes, Hjorth, \& Holt, 2014). No processo de autoconstrução, forças potenciais qualificam o processo na produção do novo. Salienta Cooper (2014) que o processo pode ser interpretado como um contínuo vir a ser de formas que estão sujeitas à sucessiva ameaça de recessão, "uma contínua antecipação do que não é presente no espaço e no tempo, a fim de se fazer presente" (p. 4). A realidade não é externa e independente da ação humana, mas é ambas, causa e efeito da "continuidade sensível que flui entre todos aspectos da existência como forças implícitas" (p. 19).

A orientação para o processo prioriza a atividade, e não o produto; mudança, e não persistência; novidade, e não continuidade; expressão, e não determinação. "Mudança, fluxo, assim como criatividade, disruptura e indeterminismo são os principais temas da visão de processo" (Langley \& Tsoukas, 2010, p. 2), que convida ao reconhecimento (mais do que à redução) da complexidade do mundo (Langley \& Tsoukas, 2010). Como ontologia relacional, foca em interações, e não em dualismos como mente e corpo, razão e emoção, individualidade e coletividade, organismos e ambiente, agência e estrutura, ética e ciência.

Por meio da visão do processo, é possível compreender como organizações surgem e como elas experimentam formas organizacionais utilizando criatividade (Hjorth et al., 2018). A abordagem da bricolagem pode representar uma possibilidade para compreender o surgimento de organizações a partir da perspectiva de processo, em uma ontologia relacional.

\section{Aspectos sobre bricolagem}

O termo bricolagem foi introduzido por Lévi-Strauss (1962), referindo-se ao modo como a população indígena criou conhecimento e compreensão do mundo em novas representações, diferindo dos parâmetros de conhecimento científico do mundo ocidental. A bricolagem é um "convite à criação fundamentada, sobretudo, na improvisação, mais do que em paradigmas científicos" (Boxenbaum \& Rouleau, 2011). Ela procura explicar como indivíduos criam conhecimento por meio de uma compreensão particular do mundo que os rodeia, o que ocorre por improvisação, mais do que pela associação a algum paradigma (Baker, Miner, \& Eesley, 2003), uma ação em um contexto, que é caracterizada pela falta de recursos e por adaptabilidade (Di Domenico, Haugh, \& Tracey, 2010). 
Bricoleurs criam valor com recursos limitados (Salunke et al., 2013). Eles procuram realizar coisas em áreas variadas, a despeito de limitações institucionais ou regulatórias (Fisher, 2012; Stinchfield, Nelson, Wood, 2013), apresentando capacidade de recombinar ou reinterpretar (Waal \& Knott, 2013). Eles são propensos a desempenhar um amplo número de tarefas (Baker et al., 2003) e "eles conduzem experiências para criar novas soluções para problemas, porém não para aperfeiçoá-las ou difundi-las" (Nelson \& Sant'anna, 2011, p. 468).

Segundo Di Domenico et al. (2010), o primeiro constructo da bricolagem é o “'making do', ou seja, o modo pelo qual bricoleurs adquirem recursos e os recombinam em novos modos para resolver problemas e responder a oportunidades" (p. 10). Esse processo envolve a criação de algo a partir do nada; a utilização de elementos ou recursos descartados, rejeitados; a utilização de recursos locais não identificados por outros. Ele consiste em uma postura diante da limitação de recursos e uma forma de criar a partir da recombinação de elementos existentes (Senyard et al., 2013). O segundo constructo é a recusa a limitações impostas pelo ambiente, e o terceiro se refere à improvisação (Di Domenico et al., 2010). Esta última é associada ao pensamento criativo, que visa combater as limitações do ambiente. Para Baker et al. (2003), a improvisação ocorre "quando o design e a execução da nova ação convergem" (p. 254), acontecendo simultaneamente. Essa situação se configura como pouca habilidade para planejar e para obter materiais, bem como em pouco tempo para buscar recursos. A improvisação é uma parte da bricolagem que pode gerar resiliência, sendo que bricolagem e resiliência são temas interligados que às vezes são utilizados como sinônimos (Di Domenico et al., 2010).

Os relacionamentos são característica importante da bricolagem. Klerk (2015) menciona a bricolagem cooperativa: "o relacionamento no qual pessoas trabalham entre si para realizar o que melhor conseguem" (p. 831). Trata-se de uma "subforma de bricolagem" (Klerk, 2015, p. 834) que envolve trabalhadores criativos em processos de cocriação e de trabalho conjunto. Klerk (2015) ressalta a importância de conexões e Baker et al. (2003) sugerem o conceito de network bricolagem, constituindo-se na "dependência de contatos preexistentes como meios em mãos"(p. 269).

No âmbito organizacional, Baker e Nelson (2005) definiram a bricolagem como "fazer com a combinação de recursos disponíveis para resolver novos problemas e aproveitar oportunidades" (p. 33). A bricolagem organizacional diz respeito ao "modo para explorar como ocorre a formação de organizações em um ambiente no qual múltiplas formas organizacionais estão disponíveis" (Perkmann \& Spiecer, 2014, p. 1786). Esses autores sugerem o modelo de bricolagem organizacional constituído por: (a) seleção - a ancoragem é derivada de um processo de seleção das formas existentes; (b) instanciação, definida como "o modo como uma forma organizacional é usada para formatar organizações emergentes" (p. 1799). A ancoragem ou fixação é constituída por três subetapas: identificação do tipo de organização como um modo natural de organização; identificação da atividade da empresa como um valor em si mesmo e identificação da atividade como rotina e prática comum.

A bricolagem organizacional é representada por: (a) nível de confiança nas habilidades em encontrar soluções para novos desafios usando recursos existentes; (b) utilização efetiva de recursos existentes para responder a novos problemas ou oportunidades; (c) habilidade em lidar com novos desafios, aplicando uma combinação de recursos próprios existentes e outros recursos baratos e disponíveis (Senyard et al., 2013). Salunke et al. (2013) mensuraram a bricolagem organizacional utilizando como variáveis: a combinação de recursos para desafiar práticas convencionais de negócios, extração de valor de recursos subutilizados e busca de soluções inovadoras.

Fisher (2012) considera a bricolagem como uma possibilidade de explicar a criação de empresas. Esta consiste em fazer algo com o que se tem em mãos, criar algo a partir de poucos recursos: fazendo, combinando recursos para novos propósitos, usando os recursos disponíveis. Por meio da utilização de habilidades específicas, o empreendedor oferece produtos ou serviços que não estariam disponíveis se não fossem ofertados pelos bricoleurs (Fisher, 2012). A bricolagem resulta na criação de novo valor para materiais simples. Ela especifica o processo central de como indivíduos agem, como: "reúnem e combinam recursos de variadas origens, que são 
investidos para se engajarem em um esforço com resultados incertos" (Perkmann \& Spiecer, 2014, p. 1786). A bricolagem proposta por Fisher (2012) consiste em: realizar algo com o que se tem em mãos e criar algo a partir do nada. "Por meio do making do com o que ele tem em mãos, o empreendedor pode alavancar recursos físicos, institucionais ou humanos de modo inovador" (Fisher, 2012, p. 1027), o que faz combinando recursos para novos propósitos com os recursos de que ele dispõe, como sintetizado no Quadro 1.

Quadro 1 - Bricolagem

\begin{tabular}{|l|l|}
\hline \multicolumn{1}{|c|}{ Bricolagem } & \multicolumn{1}{c|}{ Formas de ação } \\
\hline $\begin{array}{l}\text { Combina os recursos } \\
\text { existentes para criar soluções. }\end{array}$ & $\begin{array}{l}\text { Utiliza bens e serviços que tem em mãos para criar soluções ou resolver problemas; } \\
\text { utiliza habilidades disponíveis para criar soluções ou resolver problemas; } \\
\text { utiliza contatos existentes para criar soluções ou resolver problemas. }\end{array}$ \\
\hline $\begin{array}{l}\text { Reutiliza recursos para } \\
\text { propósitos que não foram } \\
\text { originalmente pensados. }\end{array}$ & $\begin{array}{l}\text { Por meio da criatividade, elabora novos usos e combinações com os recursos de } \\
\text { que dispõe. Utiliza materiais descartados, usados para criar novas soluções. }\end{array}$ \\
\hline $\begin{array}{l}\text { Utiliza os recursos } \\
\text { existentes. }\end{array}$ & $\begin{array}{l}\text { Prioriza o que tem em mãos, mais do que a busca de recursos de que não dispõe. } \\
\text { envolve clientes e fornecedores em projetos. } \\
\text { atua confrontando regras e padrões estabelecidos no ambiente institucional, } \\
\text { surpreendendo as pessoas. }\end{array}$ \\
\hline
\end{tabular}

Fonte: Fisher (2012, p. 1031).

A criatividade é uma característica importante para a bricolagem. Ela resulta ainda maior sob pressão (Di Domenico et al., 2010). Quando os recursos que bricoleurs têm em mãos são inadequados, eles podem abandonar oportunidades e buscar novas combinações de recursos (Baker et al., 2003), agindo de maneira criativa. Eles criam valor econômico recombinando recursos de maneira criativa. Nesse sentido, bricoleurs não são guiados pela procura de oportunidades em grande escala ou pela expansão de seus negócios. Eles são "conscientes das oportunidades locais que se apresentam mais concretamente sob a forma de elementos disponíveis, mais baratos ou gratuitos, que podem fornecer benefício econômico por meio de uma recombinação de um processamento mínimo, porém criativo" (Nelson \& Sant'anna, 2011, p. 468).

\section{Procedimentos metodológicos}

Por meio de um estudo qualitativo e exploratório, buscou-se compreender a criação e a trajetória de um circo, a partir da bricolagem. A abordagem epistemológica foi o interpretativismo, que orienta a compreensão da complexidade do mundo social e propicia ao pesquisador uma visão holística do problema (Leitch, Hill, \& Harrison, 2010).

0 método escolhido foi o estudo de caso, direcionado pelo objetivo da pesquisa (Yin, 2015). 0 tipo de estudo de caso, de acordo com Perren e Ram (2004), foi o de exploração de eventos e atores, incluindo inter-relacionamentos. Segundo Dooley (2002), um caso é extraído da vida real e tem um critério de seleção, sendo que nesta pesquisa o caso escolhido foi o de um circo por ser uma organização não tradicional, o que gera a expectativa em torno da informação nele contida (Flyvbjerg, 2006).

A coleta de dados foi realizada entre dados primários e secundários. Dados primários foram coletados em entrevistas semiestruturadas, do tipo narrativa, pois esta propicia descrições e interpretações do fenômeno na perspectiva dos participantes (Flyvbjerg, 2006). Para coleta dos dados primários, solicitou-se ao entrevistado que consentisse na participação da pesquisa, cujos objetivos foram previamente explicados. Foram realizadas três entrevistas, sendo duas face a face e uma por Skype. Cada uma delas durou em média uma hora. Foi solicitado ao entrevistado (um dos empreendedores) que narrasse a criação e o desenvolvimento do circo. Além dessas entrevistas, foi enviado um questionário por e-mail, contendo questões esclarecedoras da narrativa. Ademais, utilizaram-se 
dados secundários, sendo reportagens (20), fotos (12) e vídeos (4), bem como o website do circo. Estabeleceu-se um encadeamento de evidências a partir das fontes, que garantiu a triangulação sugerida por Flick (2009).

Quanto à validade do estudo de caso, para Yin (2015), esta compreende a validade do constructo, a validade interna e a validade externa. A validade do constructo foi assegurada por meio de múltiplas fontes de evidências: entrevistas semiestruturadas, questionário e dados secundários.

Para tratamento dos dados, inicialmente realizou-se uma codificação aberta, como sugerem Strauss e Corbin (2008), relativa ao surgimento do circo. Na sequência, o material foi analisado sob os preceitos da bricolagem e, então, foi feita uma codificação temática, com uso do software Nvivo versão 9. Identificaram-se cinco categorias explicativas: (a) o nascimento do circo: making do; (b) recusa às limitações impostas pelo ambiente; (c) a network bricolagem; (d) improvisação e mobilização; (e) reputação.

\section{Apresentação e análise dos dados}

A concepção do circo Fascínio (nome fictício) representa parte da história de vida de dois artistas acrobatas. Eles não planejaram a criação do circo. Ao contrário, seu surgimento derivou de uma série de ações improvisadas que conferiram valor cultural.

0 nascimento do circo Fascínio: making do

Dominando a arte da acrobacia, os dois artistas utilizavam a linguagem dos seus corpos para atrair a atenção do público por onde se exibiam. Eles cursaram Acrobacia na Bulgária e, neste país, onde permaneceram estudando durante três anos, aprenderam a técnica acrobata e retornaram ao seu país de origem, a Holanda. Com recursos escassos, eles começaram a apresentar shows de acrobacias nas ruas. Idealizavam a montagem do figurino, do musical e levavam o fascínio por onde passavam com o contorcionismo de seus corpos.

Com a ajuda de um amigo, eles começaram a produzir a primeira cena de acrobacia teatral. 0 pai desse amigo, que era pintor, doou para eles uma tela grande com desenho de uma floresta e animais. A tela serviu de cenário para o espetáculo, cujo enredo era o de animais, como pode ser observado no seguinte excerto do discurso: "um pintor holandês muito bom, e ele deu para nós uma tela de oito por oito, pintada à mão, com o cenário, que eram uns duendes numa floresta, e a gente pendurava isso nas árvores, em parques e viajávamos meio ano fazendo isso" (Acrobata E). Essa temática dos animais passou, desde aquele instante, a fazer parte da identidade do circo e foi incorporada posteriormente em todos os espetáculos. Eles não utilizavam animais vivos, como o circo tradicional, apenas imagens.

Foi em 1991 que eles criaram o circo. Ele começou "bem pequeno, o primeiro espetáculo era eu, meu marido e mais uma acrobata, nós éramos três" (Acrobata E). A partir dos poucos recursos de que dispunham, de seus corpos de acrobatas e com os recursos locais doados - uma tela pintada, doada por um amigo, com a imagem de uma floresta - eles criaram o primeiro espetáculo. 0 início do circo se caracteriza como um making do (Di Domenico et al., 2010), criando algo a partir de poucos recursos, utilizando elementos descartados (doados) e recursos locais que não teriam essa destinação se não fosse a criatividade e o conhecimento dos atores.

A bricolagem tem entre suas características as habilidades específicas (Fisher, 2012), sendo, neste caso, as habilidades de acrobatas. Para Perkmann e Spiecer (2014), o conhecimento e a experiência são importantes para bricoleurs. No caso do circo Fascínio, os empreendedores utilizaram o conhecimento para aproveitar os poucos recursos que tinham. Com a utilização da tela sobre a floresta, os empreendedores criaram um novo valor: um circo que não utilizava animais vivos, mas que incorporava animais na forma de imagens. 
A ancoragem ou fixação é uma das etapas da bricolagem organizacional (Perkmann \& Spiecer, 2014). No circo Fascínio, a transformação em uma organização do tipo circo ocorreu como um modo natural de arranjo organizacional, identificando a atividade como um valor em si mesmo - o circo - e identificando a atividade como rotina e prática comuns, um espetáculo com três pessoas. A associação da temática da floresta e dos animais com a atividade do circo passou a acompanhar o enredo dos espetáculos subsequentes, caracterizando-se pela não utilização de corpos de animais, e sim explorando temas da natureza e da floresta. Desde o surgimento do circo, elementos da natureza foram incorporados aos temas dos espetáculos, de modo inovador, caracterizando a relação entre bricolagem e inovação (Senyard et al., 2013).

O surgimento do circo fascínio não foi um evento planejado previamente. Ele pode ser compreendido por meio da etapa making do da bricolagem (Di Domenico et al., 2010), a partir da recombinação de recursos. A tela doada para eles pelo pintor, pai do amigo, foi um recurso importante que orientou a criação dos primeiros eventos. A entrevistada se recorda da medida da tela (oito por oito), o recurso que eles tinham em mãos e que, aliado às habilidades de acrobacia e ao apoio do amigo, trouxeram novo sentido à atividade deles, que antes desempenhavam apenas como acrobatas. Segundo Fischer (2012), a combinação de recursos, habilidades e contatos explica a criação de bricoleurs. A ação refletiu o nível de confiança dos acrobatas em suas habilidades, o que contribuiu para a solução encontrada, bem como para utilização efetiva dos recursos de que eles dispunham. Os empreendedores usaram então as habilidades de acrobatas e os recursos doados, uma bricolagem organizacional (Senyard et al., 2013).

\title{
Recusa às limitações impostas pelo ambiente
}

Três anos após a criação do circo, ele foi transformado em uma Fundação por sugestão de um amigo, o que favoreceu a obtenção de financiamentos para os espetáculos. O financiamento público foi importante para impulsionar o desenvolvimento do circo, como pode ser observado no seguinte excerto do discurso:

\begin{abstract}
A maior dificuldade foi encontrar patrocínio. Mas, a partir do momento em que a gente se tornou uma fundação e que a gente teve apoio para pedir patrocínios em nível profissional, mencionando que nós éramos uma fundação, aí foram abertos diferentes caminhos pra gente poder ter esse apoio. Então a gente teve apoio governamental para produção de espetáculos, que significa: o governo nos apoiou várias vezes, por exemplo, para pagar figurinos. Para outra produção, figurinos e cenários. Para outra produção nos pagou todo o custo de elenco. Foram diferentes tipos de patrocínio que a gente teve durante os anos. (Acrobata E)
\end{abstract}

Estudos anteriores mostraram que incentivos governamentais são utilizados para dar suporte a empresas que atuam com cultura (Galuk, Zen, Bittencourt, Mattos, \& Menezes, 2016). Como salientou a entrevistada, a limitação de recursos, principalmente para financiar figurinos, cenários e elenco, foi vencida com apoio governamental. Cordier (2007) comenta que a dependência de subvenções é uma característica do circo contemporâneo que está associada ao nível de satisfação dos espetáculos.

O financiamento foi importante principalmente nas duas primeiras décadas do circo. Desde a primeira produção eles obtiveram financiamento público integral, o que possibilitou a cobertura de gastos com figurinos e cenários. Essa produção foi exibida 120 vezes em dois anos e conquistou a premiação do Ministério da Cultura da Holanda.

Uma limitação foi a falta de acrobatas para produzir outros shows. Então, em 1994, eles criaram uma escola de circo visando selecionar e formar talentos, como mostra o seguinte trecho do discurso: 
Foi em 96 que criamos o laboratório. ... A gente atua em vários lugares com o Laboratório, porque é um tipo de estudo privado, bem diferenciado das escolas de circo normais; e porque é bem diferenciado que a gente seleciona quem participa e dá uma atenção especial, quase que privada, para cada um dos alunos. (Acrobata E)

A experiência da criação do laboratório-escola contribuiu para a formação de profissionais não apenas para o circo, mas para o mercado artístico em geral. O laboratório é uma escola itinerante que atua internacionalmente, com a oferta de módulos, diretamente supervisionada pelos empreendedores acrobatas. Desse modo, atuando como bricoleurs, eles passaram a realizar coisas em áreas variadas, a despeito de limitações institucionais ou regulatórias (Fisher, 2012; Stinchfield et al., 2013), com capacidade de recombinar ou reinterpretar o ambiente (Waal \& Knott, 2013). O laboratório-escola ampliou a atuação na área e propiciou também a internacionalização e a propagação de "discípulos", como mencionou a entrevistada: "porque você tem a oficina e, depois, eles podem continuar entrando em contato enquanto eles continuam trabalhando, até vir a próxima oficina. . . . você cria discípulos"(Acrobata E). Ressalta-se também que o laboratório é uma escola de formação, que representa um traço de circos contemporâneos que procuram desenvolver habilidades (Cordier, 2007).

Além da limitação de acrobatas no ambiente, outra foi a escassez para o financiamento de espetáculos. Eles então ampliaram o leque de atuação e passaram a realizar shows e eventos corporativos, como mostra o trecho da narrativa:

São cinco linhas de atuação ou são cinco mercados que a gente atua. Então significa que a gente não tem só um tipo de espetáculo. Então a gente pode trabalhar, por exemplo, como já fizemos várias apresentações em arenas, em estádios de futebol, por exemplo, criando ou participando de outras produções de outras pessoas ou de outras companhias, ou fazendo coprodução. (Acrobata E)

Com essas decisões o circo mostra traços do circo contemporâneo, como salienta Cordier (2007), ofertando espetáculos diversos, como shows e eventos que, no caso em estudo, foram em arenas e estádios de futebol. A produção é uma coprodução, evidenciando a importância de interações no processo (Helin et al., 2014). A resposta às limitações do ambiente ocorreu em forma de ações criativas e de ações em conjunto. Para isso, os empreendedores bricoleurs realizaram coisas em áreas variadas, como o laboratório-escola e a oferta de diferentes tipos de atividades - shows em arenas e eventos corporativos. Trata-se de resposta às limitações institucionais por meio do desempenho de um número amplo de diversas tarefas, tal como bricoleurs (Baker et al., 2003; Stinchfield et al., 2013), que buscam novas soluções para problemas (Nelson \& Sant'anna, 2011). Além disso, a expansão de atividades não foi apenas para oferecer uma resposta às limitações institucionais ou como forma de improviso (Baker et al., 2003), mas ocorreu também como forma de explorar o talento de um dos empreendedores no campo da fotografia. Ele passou a fotografar os espetáculos e eventos, sendo que, em 2016, uma de suas fotos recebeu premiação da Federação Internacional de Circo.

A network bricolagem

As networks foram importantes para a constituição do circo Fascínio. A bricolagem cooperativa, ou network bricolagem, é um recurso utilizado por artistas que atuam com criatividade (Baker et al., 2003; Klerk, 2015) e foi importante para o desenvolvimento do circo Fascínio. Klerk (2015) descreveu o papel relevante de networks em uma indústria criativa e demonstrou a contribuição destas para o desempenho de empresas do setor criativo, que constantemente se deslocam. Para Galuk et al. (2016) as networks consistem em mecanismos importantes para empresas de economia criativa inovarem. 
Um dos principais relacionamentos do circo Fascínio ocorreu com uma companhia teatral renomada, com a qual eles realizaram uma coprodução. A parceria durou oito anos e gerou diversas turnês por todo o país, como evidencia o seguinte trecho de narrativa:

Foi uma fase bem importante quando a gente fez uma coprodução com a companhia $F$, que é uma companhia holandesa de bom nome, um nome bem-conceituado, e ali foi . . . a gente abriu os horizontes, assim, artísticos da companhia, e isso aí foi em 96, e a gente prosseguiu com eles até 2004. Então foi um longo período e foi de espetáculos bem importantes ... tiveram essas duas produções com eles, fazendo turnê por todo o país. (Acrobata E)

Após esse período, outro relacionamento importante foi com um parque de diversões local. Esse relacionamento durou seis anos, de 2008 a 2014, tendo terminado em razão do fechamento do parque. Para a entrevistada, foi "um trabalho que foi bem importante, fundamental na nossa história, foram fases bem importantes" (Acrobata E).

Esses relacionamentos duradouros (oito e seis anos) contribuíram para amenizar a escassez e a limitação de recursos, tornando-se efetivamente uma bricolagem cooperativa, "um relacionamento no qual as pessoas trabalham entre si para realizar o que melhor conseguem", configurando processos de cocriação (Klerk, 2015, p. 831). A trajetória do circo foi se constituindo a partir da produção em conjunto desses atores que interagiram para continuamente se produzirem cada um individualmente e em conjunto (Helin et al., 2014; Hernes \& Weik, 2007).

Outros atores, no âmbito da network bricolagem, foram os freelancers, os quais ofereceram serviços e suporte para a realização de comerciais de televisão voltados à atração de empresas que seriam potenciais clientes. De acordo com dados da pesquisa, foi a rede, construída ao longo do tempo com freelancers que trabalhavam nos espetáculos, que favoreceu a efetivação de novos contratos para realização de shows e de eventos para empresas, assim como para apresentações em arenas e em estádios de futebol.

Os bricoleurs lidam com a integração de recursos de forma dinâmica, influenciando também seus relacionamentos. No caso do circo Fascínio, dados da pesquisa mostraram dois tipos de relacionamentos: um com a finalidade de ofertar a atividade e outro de realizar a atividade. As parcerias foram para coprodução de espetáculos e para o local de oferta (o parque). Outro tipo de relacionamento destinado à realização da atividade foi detalhado pela entrevistada: "não fazemos produção, a gente tem um time de produção" (Acrobata E). Nesse caso, os empreendedores exerceram o papel de integradores de recursos, mobilizando e organizando diferentes equipes de trabalho, como as equipes de som, iluminação, projeção e vídeo.

Improvisação e mobilização

A mobilização para o circo Fascínio sempre foi uma característica associada à preparação dos espetáculos, que era realizada em conjunto com equipes multiprofissionais. Para cada espetáculo programado, eram mobilizadas equipes de som, de luz, de projeção e vídeos. Além destas, equipes de produção, logística e administrativa eram necessárias, como mostra o trecho: "São investidos meses de trabalho e ensaios em um conceito de espetáculo antes de ser apresentado à audiência" (dados secundários). No entanto, isso não é visível ao público, pois no circo "a organização torna-se invisível para a audiência, que deseja ver a máquina em operação" (Parker, 2011, p. 567).

Cada espetáculo requer um design criativo e a mobilização da equipe de execução, como se observa no seguinte trecho: "nós criamos nossos próprios atos acrobáticos e shows. Coreografia, fotografia, vídeo, efeitos visuais, e invenção de acessórios são componentes importantes" (documento). Os empreendedores focam suas ações no processo de criação e contam com equipes parceiras para execução. A mobilização é o 
resultado de um trabalho coordenado realizado pelo casal de empreendedores. Cordier (2007) salienta que, ao trabalharem por conta própria, os artistas se encorajam de todas as facetas da atividade e "não é suficiente serem bons acrobatas, é necessário igualmente serem capazes de assegurar toda a logística, de pôr a mão na massa e fazer a empresa funcionar" (p. 19).

Improvisação, mobilização e processo criativo ocorreram de modo simultâneo. 0 processo criativo se desenrolou sob a temática dos animais, como salientado: "A gente fez, por exemplo, o carnaval dos animais, que é uma. . . na realidade, está começando a se tornar o princípio da nossa nova produção de circo e teatro" (Acrobata E). Para cada tipo de show ou evento ofertado, eles necessitavam um design criativo e, muitas vezes, era preciso improvisar. O improviso se caracteriza pela convergência entre design e execução (Baker et al., 2003). Ele pode resultar em "recombinação criativa" (Senyard et al., 2013), o que os empreendedores fazem com poucos recursos, como pode ser observado no seguinte fragmento do discurso: "fomos para a França, fomos para a Espanha, e a gente comprou um carro pequeno e fomos levando e fomos criando" (Acrobata E).

\section{Reputação}

A reputação constituiu ao longo dos anos, de acordo com a entrevistada, a explicação da sobrevivência do circo. Bricoleurs ficam atentos, pois o trabalho deles depende da reputação (Stinchfield et al., 2013). 0 seguinte excerto de discurso evidencia a importância da reputação para a trajetória do circo:

A nossa grande sorte foi o mérito, porque nós tivemos vários colegas que faliram. E nós, não aconteceu isso com a gente. . . e também eu me sinto bastante orgulhosa de a gente ter se mantido com a mesma quantidade de pessoas que estão empregadas e que pagam os seus impostos e que continuam vivendo do seu trabalho, nós fomos uma das únicas no mercado, pelo mérito conquistado durante tantos anos. Então, o que aconteceu? A quantidade de trabalho diminuiu bastante, e o que sobrou da melhor qualidade dentro do mercado, graças a Deus, veio pra nós, pelo mérito que a gente construiu durante os anos. E isso não ocorreu com outras companhias. (Acrobata E).

Como mostra o trecho anterior, a reputação assegurou a sobrevivência do circo e, para conquistá-la, foram necessários muitos anos. Ela não contribuiu para o crescimento ("orgulhosa de a gente ter nos mantido com a mesma quantidade de pessoas que estão empregadas"). Por outro lado, a reputação influenciou a conquista de clientes como a família real, conforme se observa no seguinte trecho:

Nós fizemos vários espetáculos para a rainha. Inclusive nós vamos fazer outro agora, em setembro, que vai ser a comemoração dos 200 anos do reinado, vai ser a comemoração e a gente está vinculado à família real. Porque é assim, você tem que imaginar, eles não aproximam qualquer tipo de artista da família real por duas razões: primeiro, eles têm que confiar muito na tua qualidade artística e, segundo, eles têm que confiar muito em que tipo, com que tipo de pessoas você trabalha, porque eles não podem correr nenhum risco de segurança ou de estilo ou. . . são inúmeras facetas para você poder trabalhar para a família real. (Acrobata E)

Atualmente a companhia realiza, em média, cem espetáculos anuais, incluindo os eventos, com elenco de onze acrobatas. O desenvolvimento de todos os espetáculos depende da ação e do acompanhamento dos empreendedores, o que representa um desafio para eles. E como a entrevistada salientou: "nós gostaríamos de nos clonar" (Acrobata E). Para Nelson e Sant'Anna (2011), o desenvolvimento das atividades de negócios de bricoleurs depende deles. 
O caso do circo Fascínio mostrou que, na sua trajetória, o circo não pode abandonar sua essência, alicerçada na inspiração dos envolvidos, evidenciando como o comportamento de bricoleurs é parte da sua identidade (Stinchfield et al., 2013). Os espetáculos são idealizados em torno da acrobacia. Como circo contemporâneo, a produção é uma narrativa temática sobre animais, sendo que figuras, cenários, cores e luzes complementam os espetáculos, diferenciando ou distinguindo o circo enquanto organização (Perkmann \& Spiecer, 2014). 0 Quadro 2 sintetiza as categorias analisadas no caso do circo Fascínio utilizando a bricolagem como abordagem para explicar o surgimento e a trajetória do circo.

Quadro 2 - Bricolagem no circo

\begin{tabular}{|c|c|c|}
\hline Elementos de primeira ordem & Elementos de segunda ordem & Elementos de terceira ordem \\
\hline $\begin{array}{l}\text { Acrobacia em ruas e em parques; } \\
\text { Tela pintada com motivos de animais; } \\
\text { Acrobacias; } \\
\text { Circo sobre animais, mas sem animais vivos. }\end{array}$ & $\begin{array}{l}\text { Recursos humanos escassos; } \\
\text { Elementos descartados; } \\
\text { Recursos locais; } \\
\text { Uso de habilidades específicas; } \\
\text { Criação de novo valor. }\end{array}$ & Making do \\
\hline $\begin{array}{l}\text { Busca de patrocínios e realização de } \\
\text { eventos corporativos; } \\
\text { Criação de escola de acrobatas; } \\
\text { Fotografias. }\end{array}$ & $\begin{array}{l}\text { Falta de recursos financeiros; } \\
\text { Falta de recursos humanos; }\end{array}$ & $\begin{array}{l}\text { Recusa às limitações do } \\
\text { ambiente }\end{array}$ \\
\hline $\begin{array}{l}\text { Companhia tradicional para coprodução } \\
\text { e cocriação; } \\
\text { Parceria com parque; } \\
\text { Freelancers para som, vídeo, entre outros. }\end{array}$ & $\begin{array}{l}\text { Parcerias de longa duração; } \\
\text { Parcerias para execução dos espetáculos. }\end{array}$ & Network bricolagem \\
\hline $\begin{array}{l}\text { Equipes de execução; } \\
\text { Carnaval dos animais; } \\
\text { Temas para shows corporativos. }\end{array}$ & $\begin{array}{l}\text { Mobilização; } \\
\text { Improvisação e processo criativo. }\end{array}$ & Improvisação e mobilização \\
\hline $\begin{array}{l}\text { Qualidade e sobrevivência no mercado; } \\
\text { Conquista de clientes como a família real. }\end{array}$ & Mérito e reputação. & Reputação \\
\hline
\end{tabular}

Fonte: Elaborado pela autora.

Por meio da síntese apresentada no Quadro 2, o circo teve início a partir de uma recombinação de recursos para novos propósitos e se desenvolveu devido à recusa dos empreendedores bricoleurs às limitações do ambiente. Improvisar e mobilizar recursos foram ações necessárias durante a trajetória do circo, que sobreviveu pela reputação construída.

\section{0 circo e a bricolagem}

O circo representa uma forma peculiar de organização, que incorpora uma "desordem" necessária (Parker, 2011) que o possibilite continuar sendo criativo. O significado do circo no mundo, enquanto organização, requer dos pesquisadores uma postura analítica do processo e a recusa em subjugar os limites da imaginação ao desenvolvimento técnico (Kann, 2016). Por trás de centenas de espetáculos o circo "constrói ilusão" (Parker, 2011, p. 567).

No caso do circo Fascínio, com poucos recursos e com apoio de outras pessoas e instituições, ele sobrevive por quase trinta anos. Ao longo desses anos, cada espetáculo produzido decorreu da mobilização de equipes de trabalho garantindo design e execução, de tal forma que o esforço no preparo não fosse notado na execução da atividade, pois, como salienta Parker (2011), circos precisam esconder a organização e a preparação do público para que o milagre, o espetáculo, não pareça "mero artifício" (p. 568).

$\mathrm{Na}$ trajetória do circo Fascínio os principais problemas foram: a escassez de financiamento para a criação dos espetáculos e a falta de acrobatas. Os empreendedores não se renderam a essas limitações 
(Wall \& Knott, 2013) e criaram valor (Klerk, 2015), ao mesmo tempo em que geriram equipes múltiplas para produzir e executar os espetáculos, muitas vezes "uma complexa reunião móvel" (Parker, 2011, p. 568).

Os empreendedores do circo atuaram em diversas atividades, como o circo-teatro, shows, eventos e educação de acrobatas. Um dos empreendedores passou a atuar também com fotografia dos eventos. Com isso, eles operaram como bricoleurs, desempenhando diversas tarefas (Baker et al., 2003). Com os meios que possuíam em mãos, principalmente com a expertise em acrobacia, eles criaram, executaram e propagaram a arte, do mesmo modo que Baker e Nelson (2005) e Fisher (2012) identificaram em empreendedores bricoleurs.

Bricoleurs são atores centrais de suas atividades, sendo importante seu papel de agência (Garud \& Karnoe, 2003). Nesta pesquisa, o papel de agência garantiu o design e a produção dos espetáculos, ampliando e expandindo gradualmente a atividade, com interdependência com outros atores e poucos recursos, configurando o conceito de bricolagem de Perkman e Spicer (2014), em que empreendedores "reúnem e combinam recursos de variadas origens em um esforço com resultados incertos" (p. 1786).

O surgimento do circo Fascínio pode ser explicado pelos constructos da bricolagem: making do, recusa a limitações do ambiente, improvisação e pensamento criativo. Com o que os acrobatas tinham em mãos, ou seja, com poucos recursos, eles trouxeram novos propósitos, permeados pela falta de recursos e adaptabilidade em todos os momentos da trajetória, coadunando com o conceito de bricolagem de Fisher (2012) e de Di Domenico et al. (2010). A criação do circo reflete o making do, o primeiro constructo da bricolagem ao qual se referem Di Domenico et al. (2010), a criação de algo a partir do nada ou com recursos descartados - a tela pintada e doada por um amigo utilizada para definir a temática do primeiro espetáculo, evidenciando a recombinação no ato de criação com os elementos existentes, como mencionaram Senyard et al. (2013). O segundo constructo, citado por Di Domenico et al. (2010), observado no caso do circo Fascínio, foi a recusa às limitações impostas pelo ambiente. Dois aspectos foram apontados sobre isso: a recusa à limitação de financiamento para os espetáculos e à limitação do número de acrobatas. Eles então utilizaram o improviso (terceiro construto para Di Domenico et al. 2010) e, para a escassez de financiamento, criaram uma fundação, estabeleceram relacionamentos com parques e uma grande empresa. Para a limitação da falta de acrobatas eles criaram uma escola de acrobatas. Nesse sentido, enquanto bricoleurs, eles realizaram coisas em áreas variadas, a despeito de limitações institucionais ou regulatórias, tal como mencionam Fisher (2012) e Stinchfield et al. (2013). A variedade de atividades foi observada não apenas na busca de soluções para os problemas, mas também na forma de exploração criativa, como no caso da atividade de fotografar os espetáculos. Eles criaram novo valor, por meio de diversos tipos de espetáculos (shows corporativos e em parques, escola de formação de acrobatas).

A importância dos relacionamentos, mencionada por Klerk (2015), foi corroborada nos resultados desta pesquisa. No caso da participação de equipes múltiplas, os relacionamentos evidenciaram um tipo de bricolagem cooperativa, envolvendo trabalhos criativos em processos de cocriação, como outros acrobatas, freelancers que atuavam nas áreas de som, imagem e figurinos. Além dessa bricolagem cooperativa, identificou-se também a network bricolagem, ou seja, a "dependência de contatos preexistentes como meios em mãos" (Baker et al., 2003, p. 269). 0 improviso é associado à criatividade, à necessidade de inovar em cada espetáculo, de buscar meios para implementar novas ideias e projetos. Além desses aspectos, a pesquisa mostrou a relevância do papel da reputação para o circo.

Do mesmo modo de Perkmann e Spiecer (2014), que utilizaram a bricolagem para explicar como organizações emergem, esta pesquisa mostrou como a bricolagem pode explicar a criação e a trajetória de uma organização como um circo. A bricolagem se mostrou uma abordagem explicativa para o contexto estudado, uma bricolagem baseada na combinação de recursos existentes para criar soluções, na reutilização de recursos com os quais, por meio de criatividade, os empreendedores geraram novos sentidos e usos.

Como organização singular, o circo contemporâneo, objeto deste estudo, sobreviveu durante quase três décadas em função dos sentidos atribuídos pelos acrobatas empreendedores e pelos atores que, junto com eles, construíram o circo. Ao longo da trajetória, a reputação foi sendo tecida por meio de mecanismos 
de mobilização e improvisação e, assim, os empreendedores passaram sua juventude e idade adulta entre o palco e atrás do palco, uma mobilização conjugal, deparando com a "multiplicação de tarefas, desafios do trabalho itinerante, aumento da carga horária de trabalho invisível" (Cordier, 2007, p. 18). 0 cotidiano de um circo contemporâneo pequeno se revelou, assim, um malabarismo que a bricolagem pode explicar. A reputação fez dele um circo grande. Contudo a expansão de atividades é limitada à capacidade de envolvimento dos empreendedores, que precisam estar presentes em todos os espetáculos e não podem compartilhar simultaneamente diferentes espaços e, como salientou a entrevistada: "nós precisaríamos nos clonar".

\section{Considerações finais}

Organizações culturais não são pautadas apenas pela racionalidade instrumental porque escolhas artísticas e estéticas são importantes para elas (Souza \& Carrieri, 2011). Organizações culturais enfrentam a dicotomia entre artes e mercado e precisam manter acesa a chama da criatividade, incorporando-a em suas práticas cotidianas. No caso dos circos, estes buscam a produção de emoções e, como o sentido das emoções é socialmente definido, o circo contemporâneo precisa lidar com complexidade emocional que cada vez mais é maior (Bessone, 2008), ele precisa constantemente redefinir seus processos a fim de conquistar o público e obter reputação. Esses aspectos influenciam o ordinário nas práticas de um circo, como um "extra-ordinário" (Carrieri, 2014) evidenciado pelo "meticuloso planejamento do tempo e do espaço" (Parker, 2011, p. 567) e pela busca de perfeição dos movimentos de corpos (Ramos, 2016).

Estudar o circo consiste em adentrar no universo da polifonia organizacional (Aguiar \& Carrieri, 2016). O circo não representa uma unicidade organizacional, há também uma polifonia de circos. Enquanto organização, o circo foi historicamente se remodelando e se adequando aos diferentes momentos sociais e históricos, carregando consigo traços do tradicional e do contemporâneo. O circo tradicional tinha animais, palhaços e picadeiro. O circo contemporâneo utiliza cores, brilhos, sons e efeitos para valorizar o movimento de corpos e uma multiplicidade de cenas simultâneas voltadas à produção de encantos e de emoções.

Os resultados desta pesquisa mostraram que a bricolagem representa um caminho para compreender o surgimento de organizações sob a perspectiva do processo, em uma ontologia relacional, na medida em que a coprodução, derivada das interações, foi determinante na criação e na trajetória do circo analisado. A bricolagem prioriza a expressão, e não a determinação, e foca em interações (Langley \& Tsoukas, 2010). Além disso, o enfoque da bricolagem é importante para explicar como organizações surgem e se fazem presentes utilizando a criatividade (Hjorth et al., 2018). Como pode ser observado nos resultados desta pesquisa, comportamentos associados à improvisação, adaptabilidade, criatividade e reputação foram inerentes ao surgimento e desenvolvimento do circo. Nesse sentido, a abordagem da bricolagem propiciou a compreensão de como o circo Fascínio surgiu e construiu sua trajetória. Outras abordagens que não captassem as interações sociais, as formas de coprodução de espetáculos, de improvisação e de reaproveitamento de recursos, por exemplo, não mostrariam todas as dimensões da ação necessárias para compreender a coprodução no circo contemporâneo. A bricolagem mostrou como os atores e o circo se produziram simultaneamente.

Estudos futuros podem explorar a bricolagem no âmbito de práticas voltadas a organizações de espetáculos, focando a análise para as microfundações do processo de produção de espetáculos, evidenciando de forma mais pormenorizada interações e ações de sujeitos diversos na construção da arte circense.

\section{Referências}

Aguiar, A. R. C., \& Carrieri, A. P. (2016). "Água de lona" e "sangue de serragem" nos discursos de sujeitos circenses. Organizações \& Sociedade, 23(77), 247-262. doi:10.1590/1984-9230774 
Baker, T., Miner, A., \& Eesley, D. T. (2003). Improvising firms: Bricolage, account giving and improvisational competencies in the founding process. Research Policy, 32(2), 255-276. doi:10.1016/S00487333(02)00099-9

Baker, T., \& Nelson, R. (2005). Creating something from nothing: Resource construction through entrepreneurial bricolage. Administrative Science Quarterly, 50, 329-366. doi:10.2189/asqu.2005.50.3.329

Bessone, I. (2008). Italian 'contemporary' circus in a neoliberal scenario: Artistic labour, embodied knowledge, and responsible selfhood (Doctoral dissertation). University of Turin, Turin; University of Milan, Milan.

Bolognesi, M. F. (2002). O circo "civilizado". Paper presented at the Sixth International Congress of the Brazilian Studies Association (BRASA), Atlanta, GA.

Bolognesi, M. F. (2009a). Circos e palhaços brasileiros. São Paulo, SP: Ed. Unesp.

Bolognesi, M. F. (2009b). Philip Astley e o circo moderno: Romantismo, guerras e nacionalismo. O Percevejo Online, 1(1), 1-13.

Bolognesi, M. F. (2010). O circo na história: A pluralidade circense e as revoluções Francesa e Soviética. Repertório: Teatro \& Dança, 13(15), 11-16. doi:10.9771/r.v0i15.5207

Boxenbaum, E., \& Rouleau, L. (2011). New knowledge products as bricolage: Metaphors and scripts in organizational theory. Academy of Management Review, 36(2), 272-296.

Carrieri, A. P. (2014). As gestões e as sociedades. Revista de Estudos Organizacionais e Sociedade, 1(1), 21 64.

Carrieri, A. P., Perdigão, D. A., \& Aguiar, A. R. C. (2014). A gestão ordinária dos pequenos negócios: Outro olhar sobre a gestão em estudos organizacionais. Revista de Administração, 49(4), 698-713.

Chaerki, K. F., \& Ferreira, J. M. (2016). Uma proposta de "classificação" para os estudos organizacionais no Brasil a partir de publicações entre 1997 e 2013. Revista de Estudos Organizacionais e Sociedade, 3(6), 121-176.

Cooper, R. (2014). Process and reality. In J. Helin, T. Hernes, D. Hjorth, \& R. Holt (Eds.), The Oxford handbook of process philosophy and organization studies. Oxford: Oxford University Press.

Cordier, M. (2007). Le cirquecontemporain entre rationalisation et quête d'autonomie. Sociétés Contemporaines, (66), 37-59.

Costa, M. M. F. (1999). O velho e o novo circo: Um estudo da sobrevivência organizacional pela preservação de valores institucionais (Dissertação de mestrado). Fundação Getúlio Vargas, Rio de Janeiro.

Costa, A. M., \& Saraiva, L. A. S. (2012). Hegemonic discourses on entrepreneurship as ideological mechanisms for the reproduction of capital. Organization, 19(5), 586-614. doi:10.1177/1350508412448696

Costa, A. S. M., Barros, D. F., \& Saraiva, L. A. (2014). Management industry. Cadernos Ebape.br, 12(1), 1-6.

Di Domenico, M. L., Haugh, H., \& Tracey, P. (2010). Social bricolage: Theorizing social value creation in social enterprises. Entrepreneurship Theory \& Practice, 34(4), 681-703.

Dooley, L. M. (2002). Case study research and theory building. Advances in Developing Human Resources, 4(3), 335-354. doi:10.1177/1523422302043007

Draguignan. (2018). Théâtres em dracénie: scène conventionnée dès l'enfance et pour la danse. Dossier pédagogique Le cirque. Recuperado de http://bit.ly/2HB9Ft2

Fisher, G. (2012). Effectuation, causation and bricolage: A behavioral comparison of emerging theories in Entrepreneurship Research. Entrepreneurship Theory and Practice, 36(5), 1019-1051. 
Flick, U. (2009). Introdução à pesquisa qualitativa (3a ed.). Porto Alegre, RS: Artmed.

Flyvbjerg, B. (2006). Five misunderstandings about case-study research. Qualitative Inquiry, 12(2), 219-245.

Galuk, M. B., Zen, A. C., Bittencourt, B. A., Mattos, G., \& Menezes, D. C. (2016). Innovation in creative economy micro-enterprises: A multiple case study. Revista de Administração da Mackenzie, 17(5), 166187.

Garud, R., \& Karnoe, P. (2003). Bricolage versus breakthrough: distributed and embedded agency in technology entrepreneurship. Research Policy, 32(2), 277-300.

Helin, J., Hernes, T., Hjorth, D., Holt, R. (2014). Process is how process does. In J. Helin, T. Hernes, D. Hjorth, \& R. Holt (Eds.), The Oxford handbook of process philosophy and organization studies (pp. 5-18). Oxford: Oxford University Press.

Hendry, C., \& Harborne, P. (2011). Changing the view of wind power development: More than "bricolage". Research Policy, 40, 778-789.

Hernes, T., \& Weik, E. (2007). Towards a theory of organizational becoming. In R. Lang, \& A. Schmidt, Individuum und organization: Neue trends eines organisationswissenschaftlichen forschungsfeldes. Wiesbaden: Deutscher Universitäts-Verlag.

Hjorth, D., Strati, A., Dodd, S. D., \& Weik, E. (2018). Organizational creativity, play and entrepreneurship: Introduction and framing. Organization Studies, 39(2-3), 155-168. doi:10.1177/0170840617752748

Judice, V. M. M., \& Furtado, S. C. (2014). Gestão de empreendimentos criativos e culturais: estudo de uma organização de ensino e difusão de ritmos afro-brasileiros em São João del Rei. Organizações \& Sociedade, 21(69), 293-314. doi:10.1590/S1984-92302014000200006

Kann, S. (2016). Taking back the technical contemporary circus dramaturgy beyond the logic of Mimesis (Dissertação de mestrado). Utrecht University, Utrecht.

Klerk, S. D. (2015). The creative industries: An entrepreneurial bricolage perspective. Management Decision, 53(4), 828-842.

Langley, A., \& Tsoukas, H. (2010). Introducing "Perspectives on process organizational studies". In T. Hernes, \& S. Maitlis, Perspectives on process organization studies (Vol. 1, pp. 1-26). New York: Oxford University Press.

Lavers, K., \& Burtt, J. (2017). Briefs and hot brown honey: Alternative bodies in contemporary circus. M/C Journal, 20(1), 1-3.

Leitch, C. M., Hill, F. M., \& Harrison, R. T. (2010). The philosophy and practice of interpretivist research in entrepreneurship: Quality, validation, and trust. Organizational Research Methods, 13(1), 67-84.

Leslie, D., \& Rantisi, N. M. (2011). Creativity and place in the evolution of a cultural industry: The case of Cirque du Soleil. Urban Studies Journal Limited, 48(9), 1771-1787.

Lévi-Strauss, C. (1962). The savage mind. Chicago: University of Chicago Press.

Magalhães, A. F., \& Saraiva, L. A. (2017). Amigos, amigos; negócios... não são à parte! Notas sobre a racionalidade nas organizações de trabalho. Gestão \& Planejamento, 18, 410-424.

Nelson, R. E., \& Sant'anna, A. S. (2011). Tipos de empreendedores em penturbia brasileira. Revista de Administração Pública, 46(2), 453-475.

Oliveira, J. S., \& Cavedon, N. R. (2013). Uma abordagem política das práticas cotidianas: Um estudo etnográfico num circo. Revista Interdisciplinar de Gestão Social, 2(1), 81-104. doi:10.9771/23172428rigs. v2i1.10046 
Oliveira, J. S., \& Cavedon, N. R. (2015). As tramas políticas emocionais na gênese de processos organizativos em uma organização circense. Organizações \& Sociedade, 22(72), 61-78.

Oliveira, J. S., \& Cavedon, N. R. (2017). Os circos contemporâneos como heteropias organizacionais: Uma etnografia multissituada no contexto Brasil-Canadá. Revista de Administração Contemporânea, 21(1), 142-162. doi:10.1590/1982-7849rac2017150047

Parker, M. (2011). Organizing the circus: The engineering of miracles. Organizational Studies, 32(4), 555-569. doi:10.1177/0170840611403668

Perkmann, M., \& Spicer, A. (2014). How emerging organizations take form: The role of imprinting and values in organizational bricolage. Organization Science, 25(6), 1785-1806. doi:10.1287/orsc.2014.0916

Perren, L., \& Ram, M. (2004). Case-study method in small business and entrepreneurial research mapping boundaries and perspectives. International Small Business Journal, 22(1), 83-101.

Ramos, L. E. S. (2016). Entre a proeza e a bobagem: Uma análise sociológica sobre o palhaço e o circo (Dissertação de mestrado). Universidade Federal da Paraíba, João Pessoa, PB.

Salunke, S., Weerawardena, J., \& Maccoll-Kennedy, J. R. (2013). Competing through service innovation: The role of bricolage and entrepreneurship in project-oriented firms. Journal of Business Research, 66, 1085-1097.

Seifert, R. E., \& Vizeu, F. (2015). Crescimento organizacional: Uma ideologia gerencial? Revista de Administração Contemporânea, 19(1), 127-141.

Senyard, J., Baker, T., Steffens, P., \& Davidsson, P. (2013). Bricolage as a path to innovativeness for resourceconstrained new firms. The Journal of Production Innovation Management, 31(2), 1-20. doi:10.1111/ jpim. 12091

Sicuro, L., \& Lapierre, L. (1993). École Nationale de Cirque (1993). Montreal, QC: École des Hautes Études Commerciales.

Souza, M. M. P., \& Carrieri, A. P. (2011). Racionalidades no fazer artístico: estudando a perspectiva de um grupo de teatro. Revista de Administração de Empresas, 51(4), 382-395. doi:10.1590/S003475902011000400006

Stinchfield, B. T., Nelson, R., \& Wood, M. S. (2013). Learning from Levi-Strauss' legacy: Art, craft, engineering, bricolage, and brokerage in entrepreneurship. Entrepreneurship Theory and Practice, 37(4), 889-921. doi:0.1111/j.1540-6520.2012.00523.x

Strauss, A., \& Corbin, J. (2008). Pesquisa qualitativa. Porto Alegre, RS: Artmed.

Vermon, L. (2018). Le cirque contemporain em Belgique. Recuperado de http://bit.ly/37EyrTM

Waal, G. A., \& Knott, P. (2013). Innovation tool adoption and adaptation in small technology-based firms. International Journal of Innovation Management, 17(3), 1-19. doi:10.1142/S1363919613400124

Yin, R. K. (2015). Estudo de caso, planejamento e métodos. Porto Alegre, RS: Bookman.

\section{Agradecimentos}

A autora agradece aos revisores pelas contribuições e sugestões. 


\section{Sobre a Autora}

\section{Hilka Pelizza Vier Machado}

Doutora em engenharia de produção pela Universidade Federal de Santa Catarina. Professora do Doutorado em Administração da Universidade do Oeste de Santa Catarina e do Mestrado em Gestão do Conhecimento do Centro Universitário de Maringá. E-mail: hilkavier@yahoo.com. ORCID: 0000-0002-2554-0025 